\title{
RESENHA DO LIVRO “MAGISTRATURA E ÉTICA: PERSPECTIVAS”, DE JOSÉ RENATO NALINI
}

\author{
Juliane Sant'Ana Bento ${ }^{1}$
}

Com o propósito de ser obra destinada a fornecer reflexões "da relação entre a ética com o fazer da Justiça", além de ampliar a "formação acadêmica e humana daqueles que detêm grandes responsabilidades no exercício do Poder Judiciário", a publicação Magistratura e Ética: perspectivas ainda dispõe de incontornável valor analítico, na medida em que colabora para a compreensão dos princípios que organizam a lógica interna do campo jurídico paulista, quiçá do nacional.

José Renato Nalini, à época desembargador e Corregedor Geral do Tribunal de Justiça do estado de São Paulo, hoje Secretário da Educação do governo Alckmin naquele estado, é o organizador do livro, que reúne 13 artigos de juristas, jornalistas, sociólogos e filósofos. Por ocasião do seminário Ética para o Juiz: olhar externo, realizado em setembro de 2012, promovido em razão da representação de Nalini sobre o órgão então por ele chefiado, de que não se resumiria a "vigiar, oprimir e punir", mas sim possibilitar "orientação e planejamento", veio a público pela Editora Contexto a referida obra.

Seu interesse para as Ciências Jurídicas e Sociais nacionais, se fosse preciso sublinhá-lo, é plural. Vem, primeiramente, do fato incontestável da expansão política do poder judicial no Brasil, objeto de estudo já consolidado na área, tanto devido a atuação de grupos de trabalho nos principais congressos acadêmicos, quanto pelas inúmeras publicações sobre o tema. Além disso, o livro dialoga com teses inevitáveis para a compreensão do fenômeno conforme ele se dá hoje no país: apresenta um Judiciário empreendedor da moralização política (BRIQUET; GARRAUD, 2001), denota o monopólio do sentido correto e das representações legítimas sobre a política (COMMAILLE, et al, 2010), elenca uma coleção de argumentos que desvalorizam a política e reforçam a autoridade do Direito para solucionar as crises (VAUCHEZ, 2004), e demonstra como o processo de formalização jurídica penetra no jogo político, sendo mobilizado para legitimar, ou no caso, criticar, determinados modelos de se fazer política (ENGELMANN, 2017).

Duas leituras, no mínimo, são possíveis do conjunto dos artigos reunidos: a primeira, a de que há certo consenso sobre o funcionamento da Justiça brasileira ser merecedor de uma

\footnotetext{
${ }^{1}$ Graduanda da Universidade Federal Fluminense (UFF)
} 
coleção de críticas, em razão da morosidade, da ineficiência, da burocratização, do método de recrutamento de seus membros, dos privilégios de classe e da corrupção interna, por exemplo, sem que, no entanto, sejam prejudicadas as iniciativas de proposição de melhorias e soluções pelos próprios autores; a segunda, mais homogênea, operando como justificativa da primeira, que diagnostica o fisiologismo da política nacional, o "império do favor" (p. 135), o desprezo pela coisa pública, "refúgio daqueles que não sabem distinguir o interesse público do privado" (p. 21), uma vez que a sociedade "não é representada no Parlamento e é desrespeitada pelo Executivo" (p. 40).

Dentre as críticas ao Judiciário, reconhece-se que o juiz seja "um ser humano, [...] limitado, imperfeito e falível” (p. 8), e que "no imaginário popular [...] sejam privilegiados, que recebem altos salários, [...] que gozam de sessenta dias de férias [...] e que podem ser tão sujeitos ao achincalhe da desonestidade como os desprezados políticos" (p. 42). Além disso, o "hermetismo" da magistratura, decorrente da exigência de imparcialidade que os fazem cultivar "uma assepsia que torna insensível, provido de uma couraça insuscetível a comprometimento emocional" (p. 24), é supostamente responsável pelo "surgimento de uma categoria de nefelibatas, distanciados da realidade e cônscios de que integram uma categoria distinta em relação a todos os demais" (p. 25). Entretanto, tais reprimendas aos membros dos órgãos de justiça ganham menor relevência e podem sempre ser remediadas, segundo os autores, especialmente se postas diante do quadro político brasileiro.

A política nacional é descrita num viés patológico, em que "a corrupção manifesta um desequilíbrio na estrutura federativa e nas relações entre os poderes" e o poder público “está sempre em crise, o que evidencia o Frankestein jurídico e institucional” (p. 144). Diante da falência da política, repetidas vezes anunciada pelos autores, resultado da crise ética de que padece o Brasil, os tribunais acabam erigidos à condição de "santuários onde a verdade está foragida" (p. 105), e postos no "cerne da trama política brasileira, convertendo-os em guardião de suas promessas em favor de uma sociedade justa e solidária” (p. 15).

Há, com outras palavras, a mobilização do argumento de que o juiz pode "auxiliar a transformação do atual contexto [...] se vier a assumir uma consciência consistente a respeito da potencialidade de seu protagonismo transformador" (p. 20), devendo ser "agente de transformação", "capaz de detectar iniquidades" e ser "sensível às diferenças entre as pessoas", como verdadeiro "destinatário das promessas da Constituinte de 1988 de edificação da sempre mencionada pátria justa, fraterna e solidária” (p. 25). 
O entendimento de que o papel institucional do Poder Judiciário foi modificado pelo constituinte, o qual dispôs sobre "sua presença concreta na história do país" (p. 17) é igualmente compartilhada por outro autor do livro, segundo o qual

\begin{abstract}
tanto a democracia política quanto a democracia social tem ganhado com o novo protagonismo exercido pelo Judiciário: de um lado pela imposição dos limites constitucionais à discrição do Executivo; de outro, pela ocupação do vazio deixado pelo Legislativo em matérias altamente sensíveis, que, em nome da adoção de padrões justos de convivência social, reclamam regulação, como nos casos das decisões do STF sobre as relações homoafetivas e sobre greve de servidores públicos - para citar apenas esses (Id.).
\end{abstract}

Uma ressalva que desde logo se impõe é a que diz respeito à iniciativa de promover um diálogo aberto com outras áreas do conhecimento. Por mais que em sua apresentação, o organizador sublinhe em tom de crítica o caráter "autossuficiente" do saber jurídico, e de quanto seus pares são envolvidos pelas "minúcias das técnicas processuais mais requintadas", as quais favoreceriam os "duelos de espertos" em vantagem dos que demonstram maior "habilidade para extrair o significado mais oportuno da vagueza linguística dos conceitos encerrados na produção normativa" (p. 8), é razoavelmente difícil identificar a exterioridade dos olhares que são dirigidos à relação da ética com a justiça proposta pelo livro.

Três autores são filósofos vinculados à Universidade Estadual de Campinas, outros dois atuam na Universidade de São Paulo, mesmo local de formação do sociólogo que inaugura os artigos da obra coletiva, três jornalistas estavam à época da publicação ligados ao jornal O Estado de São Paulo e dois juristas eram desembargadores do Tribunal de Justiça do estado de São Paulo. Ou seja, mesmo que comentários tenham sido tecidos por profissionais oriundos de outras áreas que não o Direito, parecem-nos bastante homogêneos, não apenas pela geografia, mas principalmente por suas considerações sobre política e sobre justiça, conforme há pouco demonstrava-se.

Adentrando no conteúdo de suas treze seções, a obra inicia pelo artigo de Luiz Werneck Vianna, relembrando pesquisa publicada em 1997 sob o título Corpo e alma da magistratura brasileira. Mostra como o contexto das reformas neoliberais promoveu mudanças "na contramão de nossa cultura jurídica, fortemente assentada na prevalência do Estado sobre a sociedade civil", tendo sido contestadas (ainda que sem grande sucesso) no Judiciário, a "nova arena para a ação política" (p. 12). Os resultados daquela pesquisa apontavam para uma tendência de envolvimento com a questão social, que o autor agora admite "impreciso", em razão do "vigoroso processo de mudança na identidade e na forma de inscrição da corporação na vida social”, com intensa juvenilização e feminização dos seus 
quadros. A percepção de que a modernização era necessária diante de um movimento de democratização das estruturas do Judiciário já constava na pesquisa, e exigiu a adoção de novos papéis pelos juízes na mudança social. Mesmo que tenha havido "a perda da aura" do juiz com o avanço da modernização do Judiciário, que hoje os faz serem vistos como servidores públicos comuns, Vianna cita Nalini quando afirma que ao juiz singular cabe o lugar de herói, desde que saiba transformar a "consciência individual" para "o verdadeiro acesso à Justiça" (p. 14). Assim, a Constituição seria contemplada, quando destinava o Judiciário "ao exercício de um papel ativo na concretização dos ideais que ela consagrara" (p. 15), mais um símbolo da força do Direito e de suas instituições em nossa história: realizar a pedagogia da virtude cívica. O novo protagonismo exercido pelo Judiciário é festejado por Vianna, salvo se houver "governo dos juízes", porque "quase todos os aspectos da vida [...] estão recobertos pela imensa, capilar e complexa trama institucional juridificada” (p. 18) resultado do processo de democratização e da "invasão generalizada da sociabilidade por parte do Direito" (p. 17).

José Renato Nalini, na sequência, explica o que vem a ser "um olhar externo" sobre a magistratura, apontando dados que o permitem atribuir ao Brasil a "patologia grave" de ser uma "nação de litigantes", o que pressuporia para o autor "uma sociedade puerilizada a necessitar da tutela do aparato judicial". Menciona o "projeto em construção" que seria o juiz, se pudesse cumprir as promessas do constituinte de "edificar uma sociedade justa, fraterna e solidária e de implementar a verdadeira democracia participativa" (p. 21). No entanto, o recrutamento dos membros por memorização frente aos desafios contemporâneos torna mais distante a efetivação da Constituição. A falta de pertencimento do juiz à "sociedade iníqua", o fato de não se sentir responsável pelas desigualdades, leva-o "ao exercício automático de um tecnicismo estéril, a proferir respostas meramente processuais a problemas reais [...] resolvendo de maneira epidérmica, periférica, sem se adentrar ao cerne do problema” (p. 22). Segundo o autor, não interessa mais a letra do texto da lei, porque a interpretação jurídica e o "que passa na mente do juiz" são mais importantes. Não existe um juiz padrão, ideal para a necessidade do ofício: há os que desempenham o papel como vocação, empenhando-se para corresponder às expectativas simbólicas; há os que entendam como emprego, esforçando-se conforme o entusiasmo.

Em "A justiça de meus sonhos", o jornalista Ethevaldo Siqueira defende que a iniciativa do seminário que deu origem ao livro analisado é a semente de uma grande mudança na justiça brasileira. Desenvolve uma enumeração do que entende como "problemas da justiça" e seus desafios, de modo a proceder a uma série de sugestões que dêem causa a 
melhoria do sistema de justiça. Dentre as alternativas propostas, vê na tecnologia digital a possibilidade de enfrentar a lentidão e a burocracia excessiva. Defende a implantação de reformas modernizantes, através de alavancas tecnológicas, que permitam otimizar o quadro de pessoal, as instalações físicas, os recursos tecnológicos, o processamento e a transmissão de dados, métodos que, segundo Siqueira, operariam a transformação do funcionamento da justiça, agora calcada em novos paradigmas de atuação, e melhorariam questões em aberto, tais como a indústria das indenizações e a brandura das penas, ainda que graves os crimes.

$\mathrm{O}$ artigo de José Nêumanne Pinto "Pela cidadania e contra a vassalagem" defende que, embora eivado de defeitos, o Poder Judiciário é aquele que tem garantido "o mínimo de poder real à sociedade” (p. 40). Reconhece que, no modelo republicado ideal, a separação e o equilíbrio entre os poderes atribuiriam papéis específicos, onde um congresso eleito debata, vote e aprove leis, outra equipe execute a vontade da maioria, e os tribunais observem o cumprimento dessas normas. Esse argumento permite a muitos congressistas denunciarem ou queixarem-se do que vem sendo tratado como "judicialização da política" (p. 37). Entretanto, diante das condições reais da "democracia à brasileira", na qual "os políticos profissionais se arrogam de não fazerem parte do universo de cidadãos iguais perante a lei” (p. 39), Nêumanne Pinto vê a intervenção judicial como garantia "da paz, da ordem, e da igualdade de direitos" no país (p. 38).

Sandro Vaia, a seu turno, em seção nomeada "Judiciário e democracia", opõe as visões defendidas pela ministra Eliana Calmon, quando ocupava o cargo de Corregedora Geral de Justiça junto ao Conselho Nacional de Justiça, as do desembargador Nalini. Segundo o autor, a primeira foi responsável por tentar ressacralizar a magistratura, criticando o corporativismo da classe e a corrupção dos "bandidos togados", incorporando "uma imagem de valente e justiceira, bem ao gosto da cultura brasileira” (p. 41). Já Nalini, por sua vez, defendia "menos punição e mais orientação na relação com os juízes" e fazia a corregedoria atuar prevenindo "os episódios que justificariam uma pena" (p. 43). O jornalista destaca, conforme pesquisa encomendada pela $\mathrm{OAB}$, que a confiança dos brasileiros na justiça só não é menor do que na "fábrica de escândalos" que seria o Congresso Nacional. Vaia sustenta que juízes vêm "percorrendo as trilhas penosas da autocrítica" sem, no entanto, lograrem diminuir o "enorme hiato entre aquilo que é percebido pela opinião pública e aquilo que de fato as instituições são na sua essência" (p. 44). Defende, por isso, que tanto mais será democrático o sistema quanto mais consolidada for a "imagem de respeito e admiração" do Poder Judiciário junto à população. 
"Por uma ética sensível" é o artigo de Willis Guerra Filho. Nele, o autor traça uma retrospectiva histórica da categoria e a defende na qualidade de "saber fundamental necessário ao nosso viver humano" (p. 46). Considera a ética, conforme a lição dos clássicos, "a disciplina que nos conduz à felicidade", na qual a "indissociabilidade entre o comportamento recomendado a cada um individualmente e o que de cada um se espera enquanto membro da comunidade política" é uma conduta correta, justa. Mobilizando a ideia kantiana do imperativo categórico e distinções renomadas entre a ética e a moral, Guerra Filho afirma nos defrontarmos hoje com uma ética "pós-convencional", na qual agregam-se elementos "da antiga ética material, fazendo convergir [...] a ética e a política em uma teoria da justiça”, ou seja, "um procedimento para se atingir soluções eticamente justificáveis para os problemas" (p. 48).

Em seguida, cabe a Renato Janine Ribeiro desenvolver a ideia da relação da ética com os juízes, e o faz enumerando exemplos "entre a poesia e a investigação", como o que consta em um filme italiano de Dino Risi de 1971, o do jornalista polonês Kapuściński, e a disputa historiográfica sobre a França renascentista. Para o autor, todos remetem "à distinção que faz Aristóteles entre poesia e história”, em que a primeira "é mais filosófica e séria" (p. 54) porque trata do universal, enquanto a última só tem compromisso com o particular. Assim, tanto o caso do juiz de instrução, personagem de Risi, que destrói provas absolutórias de um homicídio pela convicção de ter de condenar por corrupção, ainda que sem provas, quanto o caso do jornalista polonês que "inventara datas, dados e personagens" (p. 53), podem ser resultados de juízos que entendem que a verdade é mais profunda do que a mera superfície dos acontecimentos. Todavia, Janine Ribeiro afasta elementos explicativos possíveis, como o do cui prodest, "a quem beneficia". O comunismo valia-se dele para identificar quem comete o crime, indagando-se quem é beneficiado por ele, mas para o autor "é bom para investigar, mau para punir" (p. 58). Conclui, portanto, sugerindo ao juiz que "ao julgar se atenha aos fatos, seja prosaico, se preserve dos saltos audazes no trapézio da teoria" (p. 59).

O filósofo Luiz Paulo Rouanet lança, na sequência, o questionamento "Por que devemos agir moralmente?". Sustenta que um pacto moral é pressuposto de um pacto político, o que conferiria estabilidade e justiça ao longo do tempo. O problema apresentado pelo autor, o que obriga um indivíduo, dentro de uma comunidade, a agir moralmente?, é desenvolvido sobre o lastro das concepções de Kant, Habermas, K. O. Appel, Kohlberg, Rawls e mesmo Ratzinger, para ser concluído na crença de que "a única solução possível é a conciliação da moral com o Direito" (p. 67), na constituição de uma sociedade "pós-secular, pós-metafísica, 
pós-convencional" (Id.), uma vez que, segundo o autor, "o mundo é composto por pessoas que compartilham valores mínimos, e que acreditam ser possível viver em sociedade por meio do Estado de Direito" (p. 68).

Ricardo Dip, o segundo desembargador do TJSP a participar da obra coletiva, assina “Eles, os juízes, vistos por nós, os camponeses: considerações pícaras constantes de um apotegma e de uma carta de Jaume Silva Font", texto em que narra a carta em que um "camponês de Andorra" teria enviado ao soberano de seu reino, após viagens "pelas terras insuladas da Agathaurica”. Segundo reportara, após visitas às sedes de comarca, com narrativas dos casos e processos observados, "os juízes humanos são ministros de Deus, mas, custe o que custe acreditar - e muitos deles não acreditam nisso -, eles não são Deus" (p. 72). Encerra proclamando a humanidade dos julgadores, quando afirma que os juízes, "não sendo mais que homens de alma e sangue, são apenas o que são, tratando de buscar [...] o que devem ser: ministros de Deus - com a só condição de que não se persuadam de que sejam o próprio Deus" (p. 80).

O filósofo Regis de Morais, em "reflexão ética" sobre realismo e esperança, propõem-se a "redigir um breve estudo antropológico de substância ética" (p. 82), que se inicia pela pergunta originada da constatação de ser o homem "uma síntese de contradições", uma dualidade constitutiva: “o que pode auxiliar o ser humano a evitar o total desvario?". Para o autor, "esforços éticos possibilitados por uma dada estrutura de valores", além de "controle inteligente de comportamentos que beneficiem o bem comum" (p. 83) seriam o meio hábil a diminuir o paradoxo essencial do ser humano. No entanto, face à dificuldade da compreensão do que é devido e tolerável, e à "sutileza que caracteriza o existir, o coexistir e [...] o conviver dos seres humanos" (p. 84), atribui-se ao Estado a garantia dos direitos e a exigência do cumprimento de deveres dos cidadãos. E conclui em crítica aos "supercidadãos", expressão emprestada de Foucault, Ferry e Guattari, que trata daqueles que se sentem cidadãos acima da cidadania comum, uma impostura ou imaturidade, cuja vaidade os torna indisponíveis, ou com arroubos de hiperpoder, pensando nos membros de tribunais. Conforme Morais, é preciso "superar desigualdades mentais que ainda nos venham do longo escravismo, redescobrindo a grandeza do servir" (p. 92).

A continuação dos artigos dá-se com a contribuição de Sérgio Paulo Rouanet e seu "Ética e esfera pública", em que disserta sobre a questão se deve a política submeter-se às mesmas regras morais que valem na esfera privada. Aponta a visão da supremacia da moral, conforme anunciada por Kant, segundo a qual "a política está sob a jurisdição da moral” (p. 94). Opõe esta à de Maquiavel, em que a moral resta subordinada à política, e vem a ser tudo 
o que serve aos objetivos do Estado, vez que a "obrigação do Príncipe é salvaguardar o Estado", logo a política não pode "ser julgada pelas regras extrapolíticas da moral, e sim pelo critério político da eficácia” (p. 95). A controvérsia, segundo o diplomata, tem de ser resolvida no sentido de reconhecer que a política tem regras próprias, distanciando-se da moral comum, sem que dela não possa se apartar de todo, porque, se democrática, a política tem conexões com a moral comum. Tais conexões decorrem da exigência democrática da virtude cívica, consequentemente apoiada sobre virtudes da moral comum, como a probidade e a veracidade. A anomalia delas apontaria para "um déficit de democracia (p. 98), especialmente como exercida no Brasil, com perda de confiança nos representantes e nas instituições, bem como na desfactualização e na indução de mentiras e revisionismos históricos, os quais destruiriam a expectativa de veracidade e dificultariam a responsabilização de corruptos. Para o autor, portanto, os tribunais e as universidades seriam os “"santuários” onde a verdade está foragida” porque é gerada e confirmada nesses espaços, e caberia, assim, ao Judiciário um papel positivo na busca imparcial da verdade (p. 105).

Valendo-se de conceitos do pensamento de Freud e de Nietzsche, o trabalho do filósofo Oswaldo Giacoia Junior, "O pálido criminoso no veredito do Dr. Freud” trata da tese que põe fim aos "alicerces que sustentam a possibilidade de uma justificação e fundamentação ético-moral para os juízos de imputação" (p. 115). Admitir que motivações para a conduta de criminosos possam ser inconscientes é desestabilizar o fundamento que sustenta "o direito penal clássico: o conceito de livre arbítrio", em que a liberdade é entendida como causa e princípio de determinação da vontade. Em outras palavras,

na ausência de uma liberdade do arbítrio, capaz de determinar a vontade, como fator causal, levando-a a deliberar e executar ações mediante a prévia e indispensável ponderação racional de suas consequências, então perde consistência a noção tradicional de responsabilidade, fundamento de todo juízo (moral e jurídico) de imputação (p. 117).

Conclui Giacoia Junior, então, afirmando só ser possível haver "responsabilidade autêntica depois da supressão da culpabilidade, da cauterização de todo resíduo moralista”, símbolo de uma "consciência sublimada", extramoral e suprajurídica (p. 119). Aos juízes, recomenda que "a principal virtude do cético mostra-se em sua capacidade de autocontrole" (p. 123), cuja principal manifestação seria evitar proferimentos dogmáticos em juízo, sob o risco do "fanatismo devoto" conduzir à hipocrisia e à má-fé dos moralistas, às expensas dos réus. 
Encerra a obra o artigo de Roberto Romano, "Sobre o Princípio da Responsabilidade", no qual sustenta, após discorrer sobre a origem da responsabilização e da prática de checks and balances já na filosofia platônica, que no Brasil "os males vêm de longa data" (p. 145). Eles resultariam do que chama de caráter contrarrevolucionário do estado brasileiro, que perdura para manter a “desejável falta de 'accountability' governamental, legislativa, judiciária" (p. 146). Nomeia a sociedade brasileira como "império do favor" (p. 135), na qual os espaços perenes de favorecimento que são criados acabariam inviabilizando programas políticos. Por isso, seria importante "lutar contra a tirania tecnocrática" (p. 149), fazendo com que administradores e políticos respondam por seus atos.

Pelos motivos inicialmente expostos, o livro Magistratura e Ética: perspectivas, apresenta-se como leitura relevante para o esclarecimento dos princípios que orientam a lógica interna do Direito nacional, e o modo como este vem sendo colocado no cerne do jogo político mais amplo, conferindo legitimidade a determinados modelos de política.

\section{Referências Bibliográficas:}

BRIQUET, Jean-Louis; GARRAUD, Philippe. (Org.) Juger la politique: entreprises et entrepreneurs critiques de la politique. Paris: PUR, 2001.

COMMAILLE, Jacques; DUMOLIN, Laurence; ROBERT, Cécile. (Org.) La juridicisation du politique. Paris: LGDJ, 2010.

ENGELmann, Fabiano. (Org.) Sociologia Política das Instituições Judiciais. Porto Alegre: Ed. UFRGS, 2017. Disponível em: https://www.ufrgs.br/cegov/files/pub_95.pdf. Acesso em: 14 fev. 2018.

VAUCHEZ, Antoine. L'institution judiciaire remotivée: le processus d'institutionalisation d'une "nouvelle justice" en Italie (1960-2000). Paris: LGDJ, 2004. 